\title{
Excepcionalidad jurídica y gestión neoliberal. A propósito del Derecho penal
}

Legal exceptionality and neoliberal management. On the subject of Criminal Law

Bruno Vendramin ${ }^{1}$

\section{Resumen}

Desde los acontecimientos del 11 de septiembre de 2001 y la crisis financiera de 2008, la categoría excepción ha adquirido un estatuto principal en la configuración del derecho y la política mundial, puesto que pareciera que las sociedades viven en permanente estado de necesidad y urgencia. En paralelo, esta condición ha sido esgrimida por gobiernos e instituciones internacionales para impulsar y dictar un conjunto de políticas que restringen de manera considerable el contenido de los derechos y libertades individuales y, al mismo tiempo, reducen al mínimo el aspecto democrático en los procesos de tomas de decisiones. El presente artículo explora la determinación del estado de excepción en el contexto geopolítico global y se concentra en una de sus manifestaciones, cual es el derecho penal. En este campo, el terrorismo ha constituido la figura política preponderante mediante la cual determinados ordenamientos jurídicos occidentales aplican disposiciones jurídicas propias de excepción que terminan irradiando a toda la ciudadanía.

Palabras clave: Estado de excepción, Globalización, Neoliberalismo, Derecho penal, Terrorismo

\section{Abstract}

Since the events of September 11, 2001 and the financial crisis of 2008, the exception category has acquired a major status in the configuration of world law and politics, since it seems that societies live in a permanent state of need and urgency. In parallel, governments and international institutions to promote and enact a set of policies that

Recibido: 30 de julio de 2019 Aceptado: 12 de diciembre de 2019 Publicado: 20 de diciembre de 2019 1 Abogado, Universidad Nacional de Córdoba. Especialista en Derecho Constitucional, Universidad de Salamanca. Máster en Estudios Jurídicos Avanzados, Universidad de Barcelona. Doctorando en Derecho y Ciencia Política, Universidad de Barcelona. Correo electrónico: brunovendraminn@gmail.com. 
considerably restrict the content of individual rights and freedoms have wielded this condition. At the same time, minimize the democratic aspect in the processes of decision-making. This article explores the determination of the state of exception in the global geopolitical context and focuses on one of its manifestations, which is criminal law. In this field terrorism has been the preponderant political figure through which certain western legal systems apply their own legal provisions of exception that end up radiating to all citizens.

Keywords: State of Emergency - Globalization - Neoliberalism - Criminal Law Terrorism.

“A comienzos del año 69 aún regía en la provincia de Guipúzcoa el estado de excepción, pronto extendido a toda España.

Hasta mis oídos habían llegado en repetidas ocasiones aquellas palabras cuyo significado exacto desconocía [...]

Mi tío Vicente me lo confirmó por la noche en casa: -Mira, sobrino, eso es que la policía puede hacer lo que le salga de los cojones. O sea, como siempre pero aún más." (Aramburu, 2018:112-113).

\section{La excepcionalidad como expresión actual del derecho}

Desde los acontecimientos del 11 de septiembre de 2001 (en adelante, 11-S) y la crisis financiera de 2008, el término "estado de excepción" ha pasado a formar del imaginario común del derecho y la política global, en tanto existen sobrados indicios que permiten sostener que el mundo vive en permanente estado de emergencia. En consecuencia, esta condición ha sido utilizada por gobiernos e instituciones internacionales para promover y dictar una batería de políticas que restringen de manera considerable el contenido de los derechos y libertades individuales y, en ocasiones, reducen al mínimo el aspecto democrático en los procesos de tomas de decisiones. Por otra parte, la categoría ha sido utilizada por autores como herramienta analítica para describir y explicar un conjunto de fenómenos jurídicos, políticos y económicos, por lo que el término ha sido colocado en el centro de la filosofía política contemporánea, sobre todo en su vertiente continental.

El presente artículo tiene por objetivo observar la situación actual del estado de excepción y cómo este se ha cristalizado en el derecho penal. Para ello, en primer lugar, se trabajará sobre la teoría de Giorgio Agamben acerca del estado de excepción, pues, además de ser una referencia difícil de soslayar si se proyecta reflexionar sobre 
el asunto, contiene destacadas tesis para apreciar cómo se configura la aplicación del derecho en la globalización, aunque sus enunciados no están exentos de problemas. Con este supuesto, se reconstruirán las ideas que permiten sostener el por qué los órdenes jurídicos son válidos de interpretarse bajo el prisma de la excepción. Seguidamente, se presentará una crítica a dicha categoría, a los fines de justipreciar su potencia y sus límites. Posteriormente, se explicará una de las manifestaciones de la excepcionalidad jurídica, esto es, el derecho penal. Concretamente, en la teoría del derecho penal del enemigo y su recepción en algunas de las medidas jurídicas implementadas con posterioridad a los acontecimientos del 11-S.

Previo al estudio de la definición, alcance y consecuencias del término, es necesario realizar dos aclaraciones: en primer lugar, por qué Agamben escoge utilizar la locución estado de excepción y no otra, dado que las elecciones nunca son neutrales. Así, descarta de manera deliberada el uso de conceptos "estado de necesidad", "estado de sitio", "derecho especial" o "derecho de guerra" puesto que estos, en su opinión, están inevitablemente vinculados a situaciones bélicas o de conmoción interior. Estas situaciones son insuficientes e inadecuadas para desvelar la naturaleza de la serie de actos que se propondrá explicar. Estado de excepción es un "término técnico" (Agamben, 2004:13), originariamente construido en el derecho alemán (Ausnahmezustand o Nonstand) y definido y trazado sus contornos por Carl Schmitt. La segunda proposición previa que es necesario dilucidar es la relación del estado de excepción con la noción de soberanía que conduce, justamente, al pensamiento jurídico de Schmitt.

La teoría de Agamben recoge la concepción schmittiana del estado de excepción. El núcleo central de la misma es la soberanía. Según Schmitt, "soberano es quien decide sobre la excepción.” (Schmitt, 2009:13). Existe una relación estructural y constitutiva entre ambos conceptos: la soberanía, pues, está fundada en una excepción. Para Schmitt, el derecho no se deriva de una norma sino de una decisión individual e inapelable del soberano. Esta idea provoca una consecuencia singular, que más adelante se someterá a discusión: la autonomía de lo político. En efecto, el fenómeno de la decisión es, en esencia, político. Bajo este orden de ideas, lo político domina al derecho, las normas y los procedimientos. El soberano no rinde cuenta ni es responsable ante la ley ni ningún otro poder, ya sea jurídico, moral, económico o religioso.

En este sentido, el soberano no necesita estar dotado de una autoridad otorgada previamente por el derecho para crearlo: para decidir sobre la ley no necesita tener ley. Como dice Roberto Esposito, la lógica del planteamiento schmittiano se somete a la máxima del "deber fundar sin ya poder ser fundado. Deber fundar en ausencia de fundamento." (Esposito, 2012:119). Ahora bien, Agamben señala que el 
funcionamiento de la soberanía está anclado en una paradoja, que se enuncia de la siguiente manera: "el soberano está, al mismo tiempo, fuera y dentro del ordenamiento jurídico.” (Agamben, 2016:27). En última instancia, el soberano decide y declara el estado de excepción, por lo que está afuera del orden jurídico, pero, al mismo tiempo, dentro, ya que él es el responsable de tal decisión.

Hechas estas aclaraciones, Agamben entiende que el estado de excepción se configura cuando el derecho es detenido, indeterminado, neutralizado y suspendido: es un espacio "vacío de derecho, una zona de anomia en que todas las determinaciones jurídicas son desactivadas." (Agamben, 2004:75). Con ello, se genera un espacio de anomia instalado que "no está (o, por lo menos, pretende no estar) exenta de relación con el orden jurídico" (Agamben, 2004:39). Lo particular del estado de excepción es que, en términos estrictamente formales, el derecho continúa manteniendo su vigencia: "la aplicación es suspendida, pero la ley permanece, como tal, en vigor" (Agamben, 2004:49). De igual modo, no se configura ni por fuera ni por dentro del ordenamiento jurídico: es una tierra de nadie donde no es posible determinar qué es hecho y qué es derecho, qué está fuera y qué adentro, dónde se encuentra la norma y dónde la excepción. De allí que identifique en el Iustitum romano -facultad que tenía el Senado, cuando una situación ponía en peligro la República, de adoptar cualquier medida imprescindible y urgente para salvar la misma, lo que producía de inmediato la detención del derecho- el antecedente del estado de excepción moderno. De hecho, etimológicamente Iustitum significa "parada, suspensión del derecho." (Agamben, 2004:64).

Bajo este orden de ideas, el filósofo romano tiene como objetivo comprender la estructura oculta y fundamental del funcionamiento de los sistemas jurídicos occidentales. La excepción es la forma originaria del derecho, visto que éste encuentra su fundamento en una "exceptio, en una inclusión de la vida humana en la forma de vida desnuda." (Agamben, 2018:468). Con este supuesto, se dedica a construir una teoría general del estado de excepción. En este sentido, para Agamben el "espacio de excepción” (Agamben, 2016:217) por excelencia de Occidente es el campo de concentración, toda vez que este se "abre cuando el estado de excepción empieza a convertirse en la regla.” (Agamben, 2016: 215). El fundamento jurídico del campo es la proclamación del estado de excepción. En este lugar, la excepción adquiere su más alto significado, por la razón de que se funda y establece de manera nítida, como en ningún otro lugar, el poder soberano.

\section{La normalización de la excepción en los regímenes jurídicos contemporáneos}


Definida la categoría, ahora es momento de interpretar cómo se ejerce la lógica de la excepción en los ordenamientos jurídicos. En este punto, la teoría de Agamben pretende, a más de comprender el funcionamiento de los sistemas jurídicos occidentales, explicar el estado actual del derecho. Agamben argumenta que el estado de excepción es "el paradigma dominante en la política contemporánea" (Agamben, 2004:11). Desde la guerra preventiva instaurada por Estados Unidos luego de los hechos del 11-S contra el terrorismo y, como dijo el por entonces Presidente norteamericano en una arenga el 29 de enero de 2002, la existencia de un "eje del mal”, compuesto por determinados Estados y aliados terroristas, Occidente, según este discurso, se enfrenta a un enemigo que amenaza la paz, la seguridad y la libertad. Después de los atentados del 11-S, el Presidente norteamericano proclamó el estado de emergencia nacional (Proc. 7463, Declaration of National Emergency by Reason of Certain Terrorist Attacks).

Ahora bien, como aprecia Jean-Claude Paye, en este discurso habita una paradoja: se sancionan leyes, decretos y actos administrativos con carácter de urgencia pero que, en definitiva, son para una "guerra de largo recorrido contra el terrorismo." (Paye, 2008:10). Con ello, el estado de excepción se colocaría ya no como transitorio y pasajero, sino como una nueva forma de régimen político. Las medidas excepcionales tienden a adquirir el carácter de permanentes, toda vez que ningún gobierno las derogó ni intentó derogar una vez desaparecidas las amenazas terroristas. Un ejemplo de ello es la Patriot Act -como se explicará más adelante, esta ley es uno de los arquetipos de legislación de excepción-, sancionada por el Congreso de los Estados Unidos en octubre de 2001 y que se modificó recién en 2015 con la entrada en vigor de la Freedom Act.

Por otra parte, la guerra contra el terrorismo rehabilitó la teoría de Carl Schmitt sobre el amigo y enemigo, por la potestad de definir a un enemigo, que conlleva dotar de contenido político a una categoría abstracta, vaga y polisémica como es la de terrorismo. En este contexto, el Presidente de los Estados Unidos cumpliría la función de "guardián schmittiano del orden mundial." (Gordillo, 2013:86). El predominio directo de Estados Unidos sobre los países europeos se cristalizó en varios aspectos: en primer lugar, la ONU aprobó, de manera unánime, la resolución 1373, bajo la demanda de Estados Unidos, la que instaba a los países a diagramar, organizar y ejecutar planes y acciones contra el terrorismo, demanda que más de treinta Estados cumplimentaron incluyendo delitos de terrorismo en sus Códigos Penales, que antes no tenían. Por esta razón, como ha apuntado José Luis Gordillo, en las nuevas codificaciones "se entremezclan un derecho penal del hecho y un derecho penal de autor" (Gordillo, 2008:87), cuestión que se analizará con detenimiento en las páginas siguientes. En segundo lugar, los acuerdos de cooperación judicial rubricados entre 
los Estados Unidos y la UE estuvieron marcados por la presión norteamericana. Por otra parte, se determinaron sendos casos de vuelos estadounidenses que trasladaban detenidos ilegales y torturados que hacían escala en aeropuertos de la Unión Europea.

Según Agamben, el derecho público carece en la actualidad de una teoría sobre el estado de excepción. En efecto, diseñar las bases de una teoría deviene una condición preliminar para definir la relación que liga a las personas con el derecho y cómo se aplica éste por medio de la suspensión. Así pues, esta teoría tendría como objetivo principal analizar cuándo estamos ante el ejercicio de un Estado constitucional de Derecho y cuándo frente a actuaciones estatales de emergencia. Hecho que, al mismo tiempo, comporta otro problema: la declaración o no, en sentido técnico mediante una decisión gubernamental, del estado de excepción. En este sentido, Agamben apunta que la "creación voluntaria de un estado de emergencia permanente (aunque eventualmente no declarado en sentido técnico)" (Agamben, 2004:11), constituye una de las prácticas cotidianas de los Estados contemporáneos.

El adjetivo eventual es de suma importancia, pues permite interpretar una serie de ejercicios, prácticas y técnicas políticas, militares, policiales y administrativas que comparten ciertas características de los que se ejecutan en un estado de excepción pero que, en el plano estrictamente formal, no existe una declaración de tal estado. En determinados contextos, se generalizarían y normalizarían prácticas de excepción sin reconocimiento alguno por parte de los Estados. Así, la declaración del estado de excepción se sustituye por una generalización "del paradigma de la seguridad como técnica normal de gobierno" (Agamben, 2004:44). En esta dirección, Gordillo ha señalado que si el único criterio
del que se dispone es si ha habido o no una declaración oficial del estado de excepción, entonces estamos indefensos, teóricamente hablando, ante políticas que tienen unas consecuencias prácticas similares en todo lo que se refiere a la suspensión de derechos, pero que se aplican sin declaración oficial por meras razones propagandísticas (Gordillo, 2008:91).

Por esta razón, conviene hablar de espacios de excepción o, como dice Portilla Contreras, "áreas en las que desaparece el Derecho" (Portilla Contreras, 2014) o, por último, para utilizar una expresión de Juan Ramón Capella, "estado de excepción atenuado personalizado" (Capella, 1996:42), para describir escenarios del poder en los que ciertos derechos y libertades, no todos, son suspendidos temporalmente por los dispositivos y actuaciones de seguridad gubernamental. Ejemplos de ellos serían la cárcel de Guantánamo y Abu Ghraib; Camp Bonsteel en Kosovo; las prisiones secretas de la CIA en Rabat, Argel, El Cairo, Bagdad y Kabul; las áreas de detención de los aeropuertos; los campos de refugiados en Marruecos y Kenia; el campo de detención de la isla de Nauru, denominado el Guantánamo de Australia; la 
recientemente desmantelada Jungla de Calais, que fue el mayor campamento de inmigrantes y refugiados de Francia; la frontera de Estados Unidos con México; o las actuales expulsiones "en caliente" ejecutadas por el Estado español en las fronteras de Ceuta y Melilla que lindan con Marruecos.

A la vez, Agamben señala que, si existe un espacio de excepción, en el cual la vida y la norma, el hecho y el derecho, lo público y lo privado se vuelven indistinguibles, es preciso admitir que se está ante la lógica del campo de concentración, visto que materializa el estado de excepción. Igualmente, no es relevante la magnitud, gravedad o entidad de los crímenes, torturas, atrocidades y abusos que se cometan, como así tampoco el lugar, la denominación y las particularidades que revistan estos espacios. El elemento fundamental a considerar es la lógica de funcionamiento del campo de concentración: la suspensión de la ley y del orden jurídico constitucional con sus garantías. Todos los actos que se realicen en los espacios de excepción ya no son algo que dependan del derecho, sino solo "del civismo y del sentido ético de la policía que actúa provisionalmente como soberana." (Agamben, 2016:222).

Desde otro punto de vista, desde la crisis financiera de 2008, diversos autores, como Slavoj Zizek (Zizek, 2010) y Ulrich Beck (Beck, 2008), han hablado de un estado de excepción económico. Así pues, la economía mundial residiría en una especie de situación de emergencia, ya que vive al borde del colapso financiero y las medidas de austeridad se han vuelto una constante. En el contexto de la última crisis, la Unión Europea, la Comisión Europea y organismos como el Fondo Monetario Internacional, el Banco Central Europeo y el Banco Mundial, impulsaron una serie de medidas extraordinarias destinadas al ajuste del gasto público y la congelación de los salarios. Asimismo, instaron el recorte de servicios públicos, prestaciones sociales y promovieron reformas laborales con el objetivo de la flexibilización de los empleos, lo que provocó la consolidación de la nueva clase -inexistente en el siglo XX, puesto que el sujeto era la "clase obrera" o el "proletariado"- de la economía neoliberal: el precariado, esto es, personas que se encuentran bajo el umbral de la mera supervivencia. $^{2}$

\footnotetext{
${ }^{2}$ El precariado es aquel sujeto que carece de seguridades: en el empleo y en los ingresos, en el régimen de vacaciones y prestaciones sociales, en la representación política y en el futuro laboral. Así, los trabajadores de plataformas como Uber, Amazon, Deliveroo, Glovo, o las limpiadoras de hogar de Clintu o Wayook y otras formas de lo que se denomina "economía colaborativa", son algunos de los ejemplos representativos de la precariedad y la inseguridad respecto de las seguridades sociales y derechos laborales que gozaban los trabajadores en el contexto del Estado de Bienestar, forma jurídico-política que predominó hasta bien entrados los años 70. En palabras de Guy Standing, el precariado está privado de "una identidad basada en el trabajo. Cuando tienen empleo, este no es del tipo que permite una carrera profesional, sino que carece de tradiciones de memoria social y de la sensación de pertenecer a una comunidad ocupacional basada en prácticas estables, códigos éticos y normas de comportamiento, reciprocidad y fraternidad.” (Standing, 2013:34).
} 
De cualquier modo, la excepcionalidad económica no es reciente, sino que tuvo sendos antecedentes durante el siglo XX. ${ }^{3}$ Agamben apunta que, durante la Primera Guerra Mundial, en la cual la mayoría de los Estados participantes de la conflagración habían declarado el estado de excepción, "la excepcionalidad de la situación militar cediera el puesto ahora a la economía” (Agamben, 2004:25). En la actualidad, además del paquete de medidas excepcionales adoptado en los países europeos por la crisis financiera, recientemente el Presidente norteamericano ha dictado la emergencia económica para la construcción del muro en la frontera con México, con el objetivo de disponer de partidas presupuestarias extraordinarias, calculadas en 6 mil millones de dólares. ${ }^{4}$ Por otra parte, desde enero de 2016 hasta la actualidad, Venezuela ha vivido en permanente estado de excepción económica, declarándose dieciséis de prórrogas de emergencia. En el caso de Argentina, estuvo los últimos 15 años bajo emergencia económica, a raíz de la crisis financiera de 2001 y en el cual conviene recordar que se declaró el estado de sitio por las masivas protestas ciudadanas por el ajuste estructural del gasto público.

En este contexto, la excepcionalidad económica guarda íntima relación con la jurídica, puesto que la forma en las que se materializaron estas medidas económicas son leyes especiales, decretos de urgencia y reformas constitucionales, como la de España en 2011. Así, la forma clásica de regulación jurídica, es decir, la ley sancionada por los parlamentos, ha entrado en una grave crisis. En efecto, es necesario indicar que uno de los aspectos esenciales de las disposiciones sancionadas en períodos de emergencia es el crecimiento y absorción de las facultades del poder ejecutivo en detrimento de los parlamentos. Estas medidas debilitan los espacios democráticos de deliberación colectiva y lo que Kant denominó aquella facultad crítica, característica de una sociedad ilustrada, del "uso público de la razón en todos sus terrenos." (Kant, 2010:4). Si la democracia implica confrontación, crítica, discusión y el pluralismo de todas las fuerzas políticas y sociales en los procesos de tomas decisiones en una comunidad, en el estado de excepción estos se reducen al mínimo.

A la par, en la crisis económica la posición que ostentaron los técnicos al momento de tomar decisiones cobró una importancia crucial. Así, para la resolución de la misma los gobiernos y organismos supranacionales instaron el ingreso de expertos y

\footnotetext{
${ }^{3}$ En la Primera Guerra Mundial, el Presidente francés Poincarè asumió plenos poderes en materia financiera, como así también el gobierno de Laval en 1935. Por su parte, en los Estados Unidos, Roosevelt gobernó con poderes excepcionales para afrontar la Gran Depresión de 1929. De hecho, muchas disposiciones del modelo económico naciente en aquel período -el New Deal- se realizaron mediante la delegación de poderes económicos del Congreso norteamericano al Presidente.

${ }^{4}$ Cabe aclarar que el Senado norteamericano bloqueó este intento, decisión a la que el Presidente de Estados Unidos respondió con el veto y el Senado no consiguió las mayorías suficientes para anular la disposición presidencial.
} 
tecnócratas en los gobiernos de los países europeos, como en el caso de Italia y Grecia. Estos equipos gubernativos fueron los encargados de aprobar y cumplir las medidas económicas urgentes que necesitaron dichos países para el rescate de las entidades bancarias. En opinión de Geminello Preterossi, esta situación implicaría un "estado de excepción tecnocrático" (Preterossi, 2015:58), toda vez que, en el nombre de la técnica y el discurso competente, los gobiernos se enfrentaron ante un único camino: sin alternativas posibles, la única respuesta fue el ajuste del gasto público, el rescate de los bancos y la conservación del statu quo del orden capitalista.

En el contexto de la Unión Europea, la teoría que ha pretendido remediar los déficits de legitimidad democrática ha sido la gobernanza, que ha conseguido un lugar destacado en la agenda de los gobiernos, instituciones supranacionales y en la opinión pública. Este procedimiento de toma de decisiones se define por la participación de actores públicos y privados bajo relaciones abiertas y horizontales, de cuya interrelación derivan las decisiones políticas y normativas. Ahora bien, es preciso remarcar que la excepcionalidad y la gobernanza no son en estricto sentido contrarias, sino que, en ocasiones, sobre todo al momento de dictar decisiones de política económica, se yuxtaponen y entremezclan. Giovanni Messina ha demostrado esta correspondencia entre la racionalidad de la emergencia con la gobernanza.

El objetivo de Messina ha sido tomar estos dos procesos como una nueva forma de racionalidad gubernamental, en términos de Michel Foucault, esto es, una específica economía de poder que produce determinadas subjetivaciones y busca la "perfección, la maximización o la intensificación de los procesos que dirige" (Foucault, 1999:186), y los instrumentos de gobierno mediante los cuales se concretan estos objetivos "en lugar de ser leyes, van a ser tácticas diversas." (Foucault, 1999:186). En palabras de Messina:

la lógica del estado de excepción parece adaptarse muy bien a la voluntad de limitar y ahogar el debate democrático como que la lógica de la descentralización y de dispersión de los lugares de la mediación política parece haber materializado el objetivo de frustrar la eficacia de la representación política como instrumento de participación democrática (Messina, 2015:105).

Así pues, el punto de convergencia entre estas dos técnicas es el debilitamiento y el menoscabo de las instancias democráticas, toda vez que la excepcionalidad reduce los procesos de participación democrática y la gobernanza comportó la pérdida del poder político y jurídico de los parlamentos estatales, aunque sea de facto, debido a que el diseño y la producción de las decisiones queda, parcialmente, en manos de personas privadas y se realizan en lugares de lejana ubicación del control ciudadano y con escasa legitimidad democrática. La conjunción de emergencia y gobernanza ha producido, según Messina, un vaciamiento de la democracia contemporánea. 


\section{Recomposición neoliberal de la soberanía y límites del estado de excepción}

Analizada la teoría de la excepción, es forzoso señalar que la serie de actos y medidas que se desarrollan en las dinámicas descritas causan alteraciones significativas a nivel conceptual, puesto que ponen en entredicho las nociones de Estado, soberanía y derechos. Si es verdad, como ha escrito Roberto Esposito, que todas las categorías han sido ya pensadas y el trabajo filosófico no puede "tener hoy otra tarea que la de repensarlas en el interior de una red de significaciones semánticas” (Esposito, 2000:15), entonces pocos términos como los mencionados merecen una revisión crítica. Los análisis de Agamben giran en torno al modelo del Estado de Derecho, en el cual la producción y la aplicación del derecho y la declaración del estado de excepción se inscriben en el marco de la soberanía estatal y sus confines territoriales. La noción de soberanía parece cada vez menos sostenible. No obstante, en las nuevas transformaciones de la soberanía subyace un objetivo semejante que en la concepción schmittiana: la gestión gubernamental neoliberal presenta rasgos antidemocráticos y autoritarios.

La globalización neoliberal ha producido cambios estructurales en el derecho y en la política. En primer lugar, la soberanía del Estado-nación se ha visto erosionada por la liberalización de los flujos de capital, información y mercancías. Las fuerzas del capital global han producido una reconfiguración de los límites territoriales de los Estados, toda vez que la racionalidad neoliberal es, en esencia, transnacional. En este contexto, el Estado ya no puede contener, controlar y conducir los flujos económicos a sus cauces jurisdiccionales. Saskia Sassen ha descrito el escenario geopolítico global como aquel que ha "implicado una desnacionalización parcial del territorio nacional" (Sassen, 2001:16) y, al mismo tiempo, ha generado un traslado de los componentes de la soberanía del Estado a otras a entidades supranacionales y al mercado global de capitales. Consecuencia de ello, en los últimos años el crecimiento del poder de los organismos supranacionales, tales como el Fondo Monetario Internacional, el Banco Central Europeo, la Organización Mundial del Comercio o el G7 ha sido sustancial. De igual manera, una de las características de la lógica neoliberal, como subrayó Foucault hace cuarenta años (Foucault, 2007:305-359), es que ha economizado todas las esferas de la vida individual y colectiva, generando que las acciones humanas se midan con criterios pura y exclusivamente económicos. En atención a ello, en el neoliberalismo desaparece el homo politicus aristotélico para ser reemplazado por el homo oeconomicus. Entre las significativas consecuencias que este proceso ha generado, una de ellas es la sustracción del poder democrático de la ciudadanía o la deconstitución del soberano popular. Como lo político en esta etapa se expresa en 
términos económicos, el fundamento para una ciudadanía preocupada por la cosa pública se disipa. Según Wendy Brown, en la medida en que la economización de lo político y la asimilación del discurso público con la gobernanza

eliminan las categorías tanto del demos como de la soberanía, se elimina el valor -incluso la inteligibilidad- de la soberanía popular [...] En lugar de ciudadanos que comparten y disputan el poder, el orden resultante pone énfasis [...] en el consenso logrado a partir de la consulta de depositarios, grupos de enfoque, mejores prácticas y trabajo en equipo. (Brown, 2015a:289).

En la visión de Schmitt, lo político se define por la autonomía respecto del derecho, la economía, la religión y la moral. Por el contrario, en el contexto de la globalización esta situación se ha invertido, visto que las fuerzas del capital sujetan a la política y al derecho. Esta subordinación ha quedado confirmada con la crisis de 2008: los Estados debieron socorrer a los bancos y asegurar la conservación del orden financiero. Sin embargo, en paralelo a ello, la crisis también dejó en claro la importancia de los Estados, puesto que fueron vitales para la estabilización de los mercados y la facilitación de la acumulación concentrada del capital. Por esta especie de paradoja, las soberanías estatales se encuentran "limitadas, diferenciadas, disminuidas, dependientes, o endeudadas" (Giménez Merino, 2015a:34) pero, de manera simultánea, son lugares significativos de identificación simbólica y protección jurídica y política, especialmente para la ciudadanía europea.

Si bien ha existido un notorio declive de la soberanía estatal, el sistema económico neoliberal aún necesita del Estado y sus instituciones representativas para consumar los imperativos económicos de libre mercado. En efecto, en los Estados reside la representación parlamentaria y democrática, aunque haya disminuido considerablemente por los procesos explicitados. Además, siguen siendo importantes actores a nivel global, debido a que son grandes consumidores y proveedores de bienes y servicios, son las sedes de la ciudadanía, regulan la actividad económica nacional y, por ejemplo, en el ámbito del derecho penal y la política criminal, el Estado conserva importantes poderes para diseñar, administrar y ejecutar los castigos.

Con todo, si la soberanía en sentido schmittiano depende del presupuesto de la autonomía de la esfera política sobre los otros ámbitos de poder, es decir, económicos, morales y culturales y, como subraya Wendy Brown, si ya no puede abordarlos de una forma decisiva cuando es necesario, es decir, en el momento de la excepción, "no puede decirse que exista soberanía política." (Brown, 2015b:105). Por las nuevas transformaciones de la soberanía, el planteamiento de Schmitt y de Agamben no estaría en condiciones de responder a la pregunta sobre el quién, esto es, el sujeto que detenta la soberanía. En consecuencia, la declaración de la excepción, mediante un acto de conocimiento, voluntad y juicio por parte del soberano se diluiría 
considerablemente, toda vez que el soberano actual "es decisivo sin ser decisionista." (Brown, 2015b:33). La excepcionalidad actual ya no derivaría de la propia normatividad del Estado de Derecho, sino que

si en la realidad gran parte del siglo XX era posible definir un orden sociopolítico donde la violencia estatal y de las relaciones económicas quedaban limitadas nacionalmente por las constituciones e internacionalmente por el derecho internacional, en la realidad del presente asistimos a un dominio generalizado de la ley del más fuerte, sólidamente asentado sobre poderes antidemocráticos normalizados (Giménez Merino, 2015a:32).

En definitiva, con los nuevos cambios producidos en la soberanía y el derecho, se torna en extremo difícil seguir sosteniendo la idea de estado de excepción sobre la base de la soberanía estatal, puesto que ésta noción ha perdido su fuerza normativa y ha dejado de ser operativa. Como en la actualidad la soberanía se ejerce, parcialmente, en instancias que no son las propias del Estado de Derecho, resulta insuficiente postular que la suspensión del derecho -la esencia del estado de excepción- se asiente en el control de legalidad de los actos estatales, sino que debe hacerse a propósito de la nueva función que asume el Estado en la globalización neoliberal, es decir, la de un coordinador, gestor y regulador de las actividades de los poderes privados.

\section{Derecho penal de excepción. Antecedentes teoréticos}

Como se dijo al comienzo del artículo, una de las expresiones actuales de la excepcionalidad en el derecho se ha desarrollado en el ámbito del derecho penal y la política criminal. En este campo existirían dos modelos de derecho penal, estructurados bajo distintos presupuestos e inspirados por principios diferentes, como así también instituidos con objetivos y funciones disímiles: un derecho penal del ciudadano y un derecho penal del no ciudadano o enemigo. En esta instancia, el análisis se circunscribirá a la teoría del penalista alemán Gunther Jakobs, toda vez que sistematizó dicha doctrina y es uno de sus máximos exponentes.

Los antecedentes teoréticos acerca de la constitución del enemigo se encuentran desde los inicios de la civilización occidental -por ejemplo, la relación que establecieron los griegos con los bárbaros y los invasores de Oriente- y responden a diversas causas jurídicas, históricas y políticas. Ahora bien, Roberto Esposito ha identificado en el corazón de la modernidad la necesidad de instituir un enemigo. Según el filósofo napolitano, desde esta etapa Europa se pensó a sí misma contra alguien o algo, ya sea un enemigo concreto o una potencial amenaza, real o aparente. En particular, esta formulación encontraría fundamento en la teoría de Hobbes, que 
aseguraba la necesidad de conservación del orden político y, al mismo tiempo, la legitimidad de expulsar a los enemigos que se rebelen contra el Estado-Leviatán. El enemigo devino la categoría positiva necesaria para la construcción de la identidad: "el otro, lo externo, el fuera respecto al cual sólo es definible lo mismo, lo interno, el dentro." (Esposito, 1999:70).

No obstante, es en el siglo XX donde es necesario rastrear los antecedentes inmediatos sobre el derecho penal del enemigo. Francisco Muñoz Conde sostiene que los orígenes ideológicos de esta doctrina serían, fundamentalmente, dos (Muñoz Conde, 2010:19-44): en primer lugar, la dogmática penal alemana de principios y mediados del siglo XX, especialmente en el pensamiento jurídico de Franz Von Liszt, Karl Binding y Edmund Mezger. Este último postuló que en el futuro del régimen nacionalsocialista convivirían dos derechos penales: un derecho penal para la generalidad y otro derecho penal para los delincuentes por tendencia. En segundo lugar, en la filosofía jurídica de Schmitt, lugar en la cual la lógica del enemigo consuma su máximo despliegue y desarrollo. En concreto, con su teoría amigo y enemigo expuesta en El concepto de lo político (1932). Por razones de espacio, solo se explicará este último autor, puesto que, en gran medida, es en su obra donde se encuentran las principales características del derecho del enemigo.

Primeramente, lo que le interesa averiguar a Schmitt es la esencia de lo político, es decir, cuál es el criterio diferenciador específico de lo político respecto de otras esferas y actividades de la sociedad, tales como la economía, la moral y la estética. Si en la economía el criterio es la ganancia y la pérdida, en la moral lo es el bien y el mal y en la estética lo bello y lo feo, Schmitt va a postular un criterio singular para definir el fenómeno político y con ello poder determinar cuándo se está ante decisiones políticas y cuándo no. Como se explicó al comienzo del capítulo, lo político, en la filosofía schmittiana, nunca se reconduce al campo económico, moral, estético, religioso ni jurídico. Pues bien, precisamente la determinación del criterio específicamente político es lo que funda el fenómeno político.

En efecto, la diferenciación propia y decisiva de lo político es la distinción amigo y enemigo, "aquella a la que pueden reconducirse todas las acciones y motivos políticos." (Schmitt, 1998:56). Esta disociación marca el grado máximo de intensidad de la unión y la separación sin recurrir a cánones por fuera de lo político. Asumido este supuesto, para Schmitt no es en absoluto importante si el enemigo es feo, injusto o si es un malo competidor económico. En palabras de Schmitt, el enemigo es el otro, el extraño, y para determinar su esencia "basta con que sea existencialmente distinto y extraño en un sentido particularmente intensivo." (Schmitt, 1998:57). La relación que se instaura entre el amigo y el enemigo para Schmitt es puramente existencial, esto es, el enemigo es la negación total y radical del amigo. Por ello, "hay que 
rechazarlo o combatirlo para preservar la propia forma esencial de vida." (Schmitt, 1998:57).

Luego de establecer la definición propia de lo político, Schmitt procede a caracterizar al enemigo. En este sentido, la calificación, que se materializa a través de una decisión, es exclusivamente política: el enemigo no es un competidor económico ni un rival social a quien se abomina o se odia, sino que enemigo sólo es quien es "público" (Schmitt, 1998:59): un conjunto de hombres, un pueblo entero que se pone en posición de combate frente a otro. Al mismo tiempo, los pueblos se ven representados mediante los Estados. La determinación del enemigo viene dada por la necesidad de agrupar (Gruppierung) al pueblo de manera compacta y homogénea. Conjuntamente, en la dialéctica amigo-enemigo siempre está latente la posibilidad de la lucha violenta. De hecho, este vínculo adquiere su significado por el hecho de que "está en conexión con la posibilidad real de matar físicamente." (Schmitt, 1988:63). En esta dirección, José A. Estévez Araujo ha subrayado que la decisión que determina al enemigo se caracterizaría por las siguientes notas: es constitutiva, toda vez que individualiza cuáles son los intereses vitales de un pueblo en determinado momento histórico; es polémica, en el sentido original del término griego polémios (enemigo), pues dichos intereses se justifican por la indicación de un otro externo que amenaza al orden social; y, por último, es autoritaria: la autoridad adopta una decisión y la impone a los sujetos sobre los cuales ejerce poder (Estévez Araujo, 1989:137).

\section{Características del derecho penal del enemigo}

Como se señaló páginas atrás, el principal exponente de la doctrina del derecho penal del enemigo (Feindstrafrecht) ha sido y es el penalista alemán Gunther Jakobs. En efecto, la primera vez que utilizó la expresión, aunque de forma crítica y superficial, fue en 1985, en la Jornada de Penalistas Alemanes de Frankfurt. Ahora bien, en 1999, en un Congreso de Derecho Penal en Berlín, ahondó en los presupuestos, rasgos y alcances de la teoría. Esta ponencia desató una encendida polémica, como así también recibió enérgicas críticas por parte de los asistentes presentes en el Congreso. La hipótesis básica que subyace en la teoría de Jakobs es la de que, junto a un derecho penal dirigido a los ciudadanos considerados como personas, existe otro polo o tendencia del derecho penal, destinado a determinados individuos que con su conducta han abandonado de forma permanente el derecho, de tal manera que amenazan con quebrantar los fundamentos de la sociedad y el Estado.

Uno de los presupuestos que cimenta la construcción de Jakobs para justificar el derecho penal del enemigo es la noción de contrato social, que justifica a través de una singular lectura de Rosseau, Fichte, Hobbes y, sobre todo, Kant. Así pues, el enemigo es la persona que no cumple con el contrato civil (status iuridicus) que rige la 
comunidad: sus conductas son, en sí mismas, una amenaza para la sociedad. En efecto, a los delincuentes que se sitúan en guerra con el ordenamiento jurídico y que dejan de ser miembros del Estado, el derecho ya no puede tratarlos como personas. Al interpretar la filosofía jurídica de Kant sobre la relación que mantienen los ciudadanos con el Estado, Jakobs afirma que "quien no participa de la vida de un estado legal debe irse, lo que significa que es expelido (o impelido a la custodia de la seguridad)" (Jakobs y Cancio Meliá, 2006:32).

Dicho esto, Jakobs define quién es persona y quién es enemigo, puesto que ello determina la aplicación del trato discriminatorio del poder punitivo. Según el profesor de Bonn, sólo es persona "quien ofrece una garantía cognitiva suficiente de un comportamiento personal" (Jakobs y Cancio Meliá, 2006:50). El concepto de garantía o seguridad cognitiva es sumamente importante, debido a que permite identificar cuando el derecho se encuentra frente a un ciudadano y cuándo a un enemigo. El derecho penal del ciudadano se aplica a aquel individuo del que se espera una conducta conforme a las normas jurídicas, es decir, se calcula que no va a infringir las reglas, aunque eventualmente cometa algún delito. Cuando ello sucede, no pone en riesgo al Estado, ya que es un "desliz reparable" (Jakobs y Cancio Meliá, 2006:36), esto es, no niega las normas de manera radical ni permanente. En este derecho penal, la principal medida de reparación es la pena, medida que garantiza la reparación del daño y la estabilidad de la sociedad.

Por otro lado, el enemigo no ofrece un mínimo de seguridad cognitiva, no "presta fidelidad al ordenamiento jurídico" (Jakobs y Cancio Meliá, 2006:69): sus comportamientos no son previsibles conforme a las pautas que rigen la comunidad. Al no garantizarse una suficiente seguridad acerca del comportamiento futuro, la vigencia del derecho disminuye y "se convierte en una promesa vacía" (Jakobs y Cancio Meliá, 2006:38). Por esta razón, el enemigo se convierte en una fuente de peligro y en un problema de seguridad donde lo que sucede es que no se espera el cumplimiento del deber, como así tampoco "la autoadministración ordenada de la persona, de modo que desaparece el elemento central de una personalidad que presta orientación” (Jakobs y Cancio Meliá, 2006:66).

Como el enemigo no presta confianza y fiabilidad, este derecho penal combate peligros: el poder punitivo se adelanta debido a que es preciso el aseguramiento de posibles hechos delictivos futuros. Con este supuesto, se castiga no la conducta actuada y consumada, sino planeada e intencionada: "el lugar del daño actual a la vigencia de la norma es ocupado por peligros futuros.” (Jakobs y Cancio Meliá, 2006:49). Con ello, cambia la respuesta del Estado frente a estos peligros. Si en el derecho penal del ciudadano la principal herramienta para solucionar el quebrantamiento del orden es la pena, en este derecho penal son las medidas de 
seguridad que deben asegurarse de modo efectivo, a través de la coacción. Así, la lucha contra el crimen organizado requiere de medidas de seguridad eficaces por la especial peligrosidad de los sujetos perpetradores del delito. Como explica Massimo Donini, las medidas de seguridad personales son un ejemplo de este derecho penal puesto que, al presumir la peligrosidad, con ella no se dialoga ni existe la comunicación, sino que se lucha contra un peligro que sólo se "puede neutralizar o reducir." (Donini, 2007:29).

Por otra parte, dos de las características esenciales del derecho penal del enemigo es la imposición de penas y medidas de seguridad desproporcionadamente altas y “draconianas", en terminología de Jakobs y, al mismo tiempo, la disminución y supresión de garantías procesales. Este último rasgo merece especial atención. Si el ciudadano en un proceso penal es un sujeto procesal, esto es, ejerce determinadas garantías, tales como el derecho a la tutela judicial efectiva, el diligenciamiento de pruebas, estar presente y asistir a los interrogatorios, etc., en el derecho penal del enemigo éstas se disuelven para dar paso a la "desnuda coacción" (Jakobs y Cancio Meliá, 2006:45) del proceso penal. Así, la custodia de la seguridad es la mejor muestra de la coacción física que recae sobre el enemigo. Al mismo tiempo, la intervención en las comunicaciones, la extracción obligatoria de sangre, la incomunicación con el defensor, la eliminación del juez natural por la actuación de jueces o comisiones militares y otras medidas, revelan la exclusión de las garantías procesales del derecho penal del ciudadano.

Por último, las tesis de Jakobs guardan una notable proximidad con el planteamiento de Schmitt. En primer lugar, como ha apuntado Evaristo Prieto, concurriría un traslado del derecho internacional público -Schmitt- al derecho interno -Jakobs-, toda vez que la presencia del enemigo cuestiona radicalmente los fundamentos existenciales del Estado, por tanto, es necesaria la eliminación o neutralización, con todos los medios disponibles, de los agentes que alteran el orden constituido. En segundo lugar, para ambos autores el tratamiento con el enemigo no puede estar basado en derecho (Prieto Navarro, 2008:125). Asimismo, tanto la teoría de Schmitt como de Jakobs se centran en el caso límite y anormal que subyace en el corazón del orden jurídico: en el primero es la excepción la que determina el orden jurídico, mientras que en el segundo se pone en juego el incumplimiento del derecho por la inseguridad cognitiva del enemigo. Por último, como ha reclamado Cancio Meliá, las medidas del derecho penal del enemigo deben ser trasladadas "al ámbito de discusión política correcto: a las medidas en estado de excepción.” (Jakobs y Cancio Meliá, 2006:19).

\section{Casos concretos del derecho de excepción}


En el diseño de la política criminal, principalmente después de los acontecimientos del 11-S, ha habido una creciente "expansión del derecho penal" (Silva Sánchez, 2011), y existen significativos muestras y ejemplos tanto en la legislación como en disposiciones administrativas de medidas que responden a las características del derecho penal del enemigo. En este sentido, el terrorismo es un caso paradigmático de la aplicación de un derecho penal de excepción. Al mismo tiempo, el inmigrante clandestino también es objeto de políticas punitivas que no lo reconocen como ciudadano sino como enemigo. En este punto, sólo se observará el tratamiento del terrorista en determinados Estados occidentales.

Como cuestión previa es necesario apuntar que, como ha señalado Donini, el derecho penal del enemigo parece dibujado a medida del terrorista islámico (Donini, 2008:47). La razón de ello es que con el terrorista islámico no se entabla ningún tipo de diálogo ni comunicación en derecho porque niega de manera absoluta y radical los fundamentos del Estado y los derechos fundamentales de los ciudadanos. Como se dijo en el primer apartado, la mayoría de países europeos, luego de los acontecimientos del 11-S, sancionaron rápidamente leyes e introdujeron reformas en los códigos penales con el fin de tipificar delitos asociados al terrorismo. Una de las bases fundamentales de las reformas la constituyó la Decisión Marco del Consejo de la UE de 13 de junio de 2002 sobre lucha contra el terrorismo (2002/475/JAI), que introdujo por primera vez una definición común de delito de terrorismo para todos los Estados miembros.

En esta dirección, Inglaterra sancionó, el 14 de diciembre de 2001, la Antiterrorism, Crime and Security Act, en la cual se autorizaba la detención indefinida de extranjeros sospechosos de actividades terroristas. Luego de los atentados terroristas en Londres el 07 de julio de 2005, el Parlamento británico emitió la Terrorism Bill en 2006, donde se introdujo el delito de "incitación indirecta al terrorismo", que consiste en una declaración verbal o escrita que enaltezca al terrorismo, aunque no defienda directamente la violencia ni se realice una apología concreta del delito. Por último, cabe señalar que en 2016 se aprobó la Investigatory Powers Bill, que dispone, entre otras medidas, que las compañías de comunicación almacenen los datos de los usuarios durante 12 meses para que los servicios de seguridad accedan a dicha información, como así también autoriza a cuerpos de seguridad el hackeo de móviles, ordenadores, redes y servicios en la nube, medidas todas justificadas por las amenazas terroristas. En Estados Unidos, en octubre de 2001 se sancionó la Patriot Act, que incorporó medidas propias de un derecho de excepción, por ejemplo la facultad del FBI de detener a inmigrantes sospechosos que representen un peligro para la seguridad de Estados Unidos y permitía a la Agencia de Seguridad Nacional interceptar líneas telefónicas y correos electrónicos de los ciudadanos estadounidenses sin autorización 
judicial previa. Por otro lado, uno de los ejemplos inequívocos de este tipo de derecho penal lo constituyó la military order dictada por el 13 de noviembre de 2001 por el Presidente de los Estados Unidos. Al establecerse una jurisdicción militar para terroristas, se les dio a éstos la calificación de combatiente enemigo, por tanto, al momento de ser capturados, no gozaban de la condición de prisioneros de guerra conforme las disposiciones de los Convenios de Ginebra de 1949.

En esta orden se cristalizan las características delineadas por Jakobs: en un contexto de guerra preventiva donde se produce un adelantamiento de la punibilidad, el tratamiento otorgado al enemigo combatiente es el de no persona, ya que quedaba excluido de toda determinación jurídica. Asimismo, se disminuyeron las garantías procesales, como la del juez natural, suprimida por los tribunales militares. Por último, la principal medida de seguridad era la privación de la libertad, especialmente en la cárcel de Guantánamo. El trato con éstos detenidos ya no se rige por el derecho sino que, como afirma Agamben, son "objeto de una pura dominación de hecho." (Agamben, 2004:13).

Por su parte, desde los atentados en París acaecidos el 13 noviembre de 2015, Francia vivió bajo un permanente estado de excepción, declarado mediante el Decreto 20151475 con una duración, en principio, hasta enero de 2016. Posteriormente, el gobierno francés lo prorrogó seis veces, hasta el 01 de noviembre de 2017, fecha en que entró en vigencia la Ley Renforçant la sécurité intérieure et la lutte contre le terrorisme. Esta ley trasladó disposiciones excepcionales al derecho común. Entre las más significativas, cabe destacar que el Ministerio del Interior posee la facultad de ordenar arrestos domiciliarios a cualquier individuo por "razones serias" que hagan pensar que su comportamiento constituye una amenaza para el orden público. ¿Quién define qué son "razones serias"? La indeterminación de la fórmula abre el espacio para el ejercicio arbitrario y discrecional de la policía que actúa como soberana: otra de las medidas que consagró la ley fue la de otorgar la potestad de cerrar lugares de cultos en los que circulen ideas, escritos o teorías que "fomenten la violencia o el terrorismo", como así también prohibir que cualquier sujeto salga de su municipio o provincia.

En el caso de Turquía, a raíz del fallido golpe de Estado intentado contra el Presidente Erdogan el 15 de julio de 2016, por facciones de las Fuerzas Armadas turcas con la supuesta connivencia del Movimiento Gullen, calificado como terrorista por el Gobierno turco, se declaró el estado de excepción. Inicialmente declarado por tres meses y prorrogado siete veces, el presidente turco gobernó por decreto e impuso medidas restrictivas de las libertades de ciudadanos turcos y extranjeros. En concreto, se calcula que unas 160.000 personas fueron tomadas en custodia y más de 70.000 fueron detenidas por tener vínculos con organizaciones terroristas. Al mismo 
tiempo, fueron destituidos más de 100.000 jueces, funcionarios públicos y docentes de universidades, como así también la prensa se vio fuertemente reprimida, dado que se cerraron más de 70 periódicos, revistas, radios y canales de televisión. (DW.com, 2018).

España no ha sido ajena en tratar al terrorista como enemigo, instituyendo medidas punitivas diferentes para castigar los delitos vinculados al terrorismo respecto del derecho penal aplicable a los ciudadanos. Como primera cuestión, cabe apuntar que, desde la década del 70, con la actuación de bandas terroristas como ETA y GRAPO, el Estado español comenzó a diseñar una legislación penal especial. En cierto sentido, esta legislación constituye jurídicamente un precedente de las actuales, pero los contextos son considerablemente distintos. En efecto, las sucesivas modificaciones ocurridas desde 2003 -en particular, las más relevantes, la de 2003, 2010 y 2015- en el Código Penal español (en adelante, CP) dan prueba de la creciente y expansiva tendencia legislativa en aras del derecho penal del enemigo.

Por ejemplo, respecto de la libertad condicional, el artículo 78 agrava los plazos para otorgar dicha libertad a los condenados por delitos vinculados al terrorismo. Asimismo, el artículo 90, punto 8, prescribe que para que los terroristas disfruten la libertad condicional, requiere un plus de actividad por parte del condenado, toda vez que exige que muestre signos "inequívocos" de haber abandonado los fines terroristas y haya colaborado activamente para impedir otros delitos terroristas, o para la identificación, captura y procesamiento de responsables terroristas. Todas estas medidas persiguen la neutralización o inocuización del terrorista.

Por otra parte, existen tipos penales que reflejan un indudable adelantamiento de la punibilidad. El artículo 575 punto 1 ha tipificado las conductas de los llamados "lobos solitarios yihadistas", ya que castiga a quien tenga la finalidad de capacitarse o recibir adoctrinamiento para cometer delitos terroristas. El punto 2 dispone que penará a quien acceda de manera "habitual" a servicios de comunicación o contenidos de internet que estén dirigidos a la incitación a la incorporación a un grupo terrorista. El artículo 578 sanciona el enaltecimiento o la justificación por cualquier medio de expresión pública o difusión de los delitos terroristas, o la realización de actos que entrañen descrédito, menosprecio o humillación de las víctimas de delitos terroristas o sus familiares. Por último, el artículo 579 bis, punto 2, prevé que se le impongan al terrorista, además de la pena privativa de libertad, una medida de libertad vigilada de cinco a diez años en el caso de una pena grave y de uno a cinco en una pena menos grave, agravantes que no existen para el resto de delitos comunes.

\section{Consideraciones finales}


Como se explicó a lo largo del artículo, el estado de excepción, que en opinión de Agamben ha consumado en el presente su máximo desarrollo, convive en el seno de los ordenamientos jurídicos occidentales. Asimismo, se puso de relieve la necesidad de atender a las nuevas transformaciones de la soberanía en la globalización neoliberal, ya que el estado de excepción está anclado en la noción de soberanía. En este sentido, Agamben no presta la suficiente atención a los factores económicos y sociológicos que han originado el debilitamiento y la eclosión de la soberanía estatal. Por otra parte, se observó que una de las manifestaciones preponderantes de la excepcionalidad jurídica es el derecho penal y cómo este, en ocasiones, distingue entre un derecho penal del ciudadano y un derecho penal del enemigo, disociación que es notoria en ámbitos como el terrorismo. Desde la postulación de estos dos derechos se abre una fisura en el orden jurídico y se ponen en entredicho los fundamentos mismos del Estado de Derecho para dar paso a una legislación de combate, como las adoptadas por algunos Estados occidentales.

En el medio de esta fractura, es necesario remarcar que la imbricación entre el estado de excepción y el derecho del enemigo provoca la suspensión de las garantías y principios que vertebran los Estados de Derecho. En particular, esta conjunción se ha materializado a través del concepto de seguridad, pues en la actualidad el estado de seguridad ha sido la forma mediante el cual se ha prolongado el estado de excepción (Agamben, 2015). A raíz de ello, la seguridad ha cobrado una prioridad indiscutible y ha relegado a la libertad a segundo plano. Si la dialéctica libertad-seguridad ha trazado, desde Hobbes en adelante, uno de los itinerarios centrales de la filosofía política moderna, en el presente se ha decantado decididamente por la seguridad, puesto que ésta ha adquirido un valor autónomo: el derecho se centra preferentemente en la prevención de los riesgos como sistema de control social y, de manera secundaria, en la protección de bienes jurídicos. La consecuencia inevitable del crecimiento de la seguridad es una mayor restricción de la libertad.

En tanto, el derecho penal, al ser uno de los campos principales en los cuales se observa de manera nítida la deriva securitaria, identifica a ciertos sujetos como enemigos buscando su neutralización con medidas eficientes alejadas de los parámetros garantistas, produciéndose un sutil deslizamiento del derecho penal liberal a la lógica de la guerra, pues conviene recordar que diversos atentados terroristas fueron declarados actos de guerra y no como crímenes comunes. Justamente, la razón del Estado de Derecho es la negación frontal de la idea del enemigo. Este tipo de Estado no admite el binomio amigo-enemigo. Más aún: una guerra contra el terrorismo es, en esencia, una contradicción en los términos, ya que, al menos en su teorización clásica, la guerra se definía por la posibilidad de establecer un enemigo cierto y determinado. Por el contrario, el estado de seguridad descansa 
en la premisa de que "el enemigo debe permanecer en lo vago, para que cualquiera en el interior, pero también en el exterior- pueda ser identificado como tal." (Agamben, 2015:4). Para el Estado de seguridad, cualquier persona o ciudadano es un terrorista en potencia. La única y excluyente alternativa con la cual deben los Estados responder ante el terrorismo es el derecho, basado en un juicio justo y una serie de garantías procesales y sustanciales, en los cuales se castigue los hechos delictivos consumados y no sea relevante la personalidad, actitud o pensamientos "peligrosos" de los autores, si es que se quiere salvaguardar la paz y la democracia misma.

\section{Bibliografía}

- AGAMBEN, G. (2018). El uso de los cuerpos. Homo sacer IV, 2. Buenos Aires: Adriana Hidalgo.

- AGAMBEN, G. (2004). Estado de excepción. Homo sacer II, 1. Valencia: Pretextos.

- $\quad$ AGAMBEN, G. (2015). “Del Estado de Derecho al Estado de seguridad”. París: Le Monde.

- AGAMBEN, G. (2016). Homo sacer. El poder soberano y la nuda vida. Valencia: Pretextos.

- ARAMBURU, F. (2018). Años lentos. Barcelona: Tusquets.

- BECK, U. (2008). “Estado de excepción económico”, Madrid: El País.

- BROWN, W. (2015a). El pueblo sin atributos. La secreta revolución del neoliberalismo. Barcelona: Malpaso.

- BROWN, W. (2015b). Estados amurallados, soberanía en declive. Barcelona: Herder.

- CAPELLA, J.R. (1996). “Un estado de excepción atenuado personalizado”, en Grandes esperanzas. Ensayos de análisis politico. Madrid: Trotta.

- DONINI, M. (2008). "Derecho penal de lucha. Lo que el debate sobre el Derecho penal del enemigo no debe limitarse a exorcizar", en Politica criminal en vanguardia. Inmigración clandestina, terrorismo, criminalidad organizada. Madrid: Thomson Civitas.

- DONINI, M. (2007). "El derecho penal frente al enemigo", en Derecho penal de excepción. Terrorismo e inmigración. Valencia: Tirant lo Blanch.

- DW.com (2018). "Balance del estado de excepción en Turquía”. Disponible en https://www.dw.com/es/balance-del-estado-de-excepci\%C3\%B3n-enturqu\%C3\%ADa/a-44717117-0.

- ESPOSITO, R. (2010). Diez pensamientos acerca de la política. Buenos Aires: Fondo de cultura económica. 
- ESPOSITO, R. (1999). "Enemigo, extranjero, comunidad”, en Los filósofos y la politica. México D.F.: Fondo de cultura económica.

- ESPOSITO, R. (2000). “La perspectiva de lo impolítico”. Córdoba: Revista Nombres.

- ESTÉVEZ ARAUJO, J.A. (1989). La crisis del Estado de Derecho liberal. Schmitt en Weimar. Barcelona: Ariel.

- FOUCAULT, M. (1999). "La gubernamentalidad", en Estética, ética y hermenéutica. Obras esenciales. Barcelona: Paidós.

- FOUCAUlT, M. (2007). Nacimiento de la biopolitica. Curso en el College de France (1978-1979). Buenos Aires: Fondo de cultura económica.

- GIMENEZ MERINO, A. (2015a). "De la excepcionalidad persistente a la normalización de la plutocracia”, en La democracia en bancarrota. Madrid: Trotta.

- GORDILLO, J.L. (2008). “Globalización, terror, derechos”, en Nostalgia de otro futuro. La lucha por la paz en la postguerra fría. Madrid: Trotta.

- GORDILLO, J.L. (2013). "Leviatán sin bridas. Sobre la demolición controlada de las instituciones mentales que limitan el uso estatal de la fuerza”, en El libro de los deberes. Las debilidades e insuficiencias de la estrategia de los derechos. Madrid: Trotta.

- JAKOBS, G. y CANCIO MELIÁ, M. (2006). Derecho penal del enemigo. Madrid: Thomson Civitas.

- MUÑOZ CONDE, F. (2010). Los orígenes ideológicos del derecho penal del enemigo. México D.F.: Ubijus.

- PAYE, J.C. (2008). El final del Estado de Derecho. La lucha antiterrorista: del estado de excepción a la dictadura. Guipuzcoa: Hiru.

- PORTIlla CONTRERAS, G. (2007). El Derecho Penal entre el cosmopolitismo universalista y el relativismo posmodernista. Valencia: Tirant lo Blanch.

- PORTILlA CONTRERAS, G. (2014). "Terroristas como no-personas del Derecho. ¿Es delito la tortura de presuntos terroristas?”, Barcelona: Mientras tanto.

- PRETEROSSI, G. (2015). “¿Vive el Estado democrático de presupuestos que ya no es capaz de garantizar?", en La democracia en bancarrota. Madrid: Trotta.

- PRIETO NAVARRO, E. (2008). "Excepción y normalidad como categorías de lo político", en Politica criminal en vanguardia. Inmigración clandestina, terrorismo, criminalidad organizada. Madrid: Thomson Civitas.

- SASSEN, S. (2001). ¿Perdiendo el control?: la soberanía en la era de la globalización. Barcelona: Bellatera.

- SCHMITT, C. (1998). El concepto de lo politico. Madrid: Alianza. 
- SCHMITT, C. (2009). Teología política. Madrid: Trotta.

- SILVA SÁNCHEZ, J.M. (2011). La expansión del derecho penal. Aspectos de la politica criminal en las sociedades postindustriales. Buenos Aires: B de F.

- STANDING, G. (2013). El precariado. Una nueva clase social. Barcelona: Ediciones de pasado y presente.

- ZIZEK, S. (2010). “Un permanente estado de excepción económica”. Londres: New Left Review. 